\title{
PUBLICIDADE LOTÉRICA: UMA ANÁLISE DAS PROMOÇÕES COMERCIAIS SOB ASPECTOS DA RESPONSABILIDADE SOCIAL CORPORATIVA, DIREITO DO CONSUMIDOR E PROTEÇÃO A DADOS PESSOAIS
}

\author{
MARKETING USING LOTTERY: \\ AN ANALYSIS OF THE COMMERCIAL CAMPAIGNS CONSIDERING ASPECTS OF SOCIAL \\ CORPORATE RESPONSIBILITY, CONSUMER RIGHTS AND PROTECTION OF PERSONAL \\ DATA
}

\section{Danielle Mendes Thame Denny}

\begin{abstract}
Professora na Fundação Armando Alvares Penteado e na Universidade Paulista. Pesquisadoraassociadavisitante do
Whitney and Betty MacMillan Center for International and Area Studies na Yale University, EUA. Doutora em

Direito Ambiental Internacional pela UNISANTOS com bolsa da Coordenação de Aperfeiçoamento de Pessoal de

Nível Superior.

E-mail: danielle.denny@gmail.com
\end{abstract}

Gabriel Leão

Mestre em Comunicação na Contemporaneidade pela Faculdade Cásper Líbero. Especialista em Política e Relações Internacionais pela Fundação Escola de Sociologia e Política de São Paulo. Repórter, produtor e diretor.

E-mail: gabcsn@gmail.com

Recebido em: 04/04/2019

Aprovado em: 27/06/2019

RESUMO: Este artigo descreve o contexto de comércio digital e a importância dos dados para viabilização das relações econômicas;uso das promoções comerciais como ferramentas publicitáriase coletora de dados e dos marcos regulatórios para a proteção de dados pessoais brasileiros e europeus; o potencial da Secretaria de Acompanhamento Fiscal, Energia e Loteria em contribuir na criação de valores sociais; erecentes promoções comerciais autorizadas, sob o prisma da proteção de dados dos participantes;concluindo que pouquíssimo foi exigido das empresas para evitar indevido uso desses dados e que grande maioria não dispõe em seus regulamentos detalhes da utilização dos mesmos. O método empregado é o hipotético-dedutivo, com estudo de caso, levantamento de legislação e doutrina nacional e internacional. Não foi encontrada jurisprudência pertinente. Os resultados apontam apenas três dos casos estudados mencionandosuperficialmente como os dados serão tratados,os demais casos se limitam a solicitar a autorização do uso de imagem e voz. O Brasil dispõe de proteção dispersa e a partir de 2020 também de específica sobre o tema proteção de dados. A Diretiva Europeia de Proteção de Dados Pessoais já opera. Se conclui que aproliferação do uso das promoções comerciais para coleta de dados, crescimento do volume de negócios digitais e utilização de novas tecnologias para a publicidade pressiona para existência de marcos legais específicos,porémdemandantes dos órgãos públicos cobrandoobservação preventiva, estabelecendo um paradigma jurídico administrativo condutor para maior responsabilidade social corporativa e mais desenvolvimento tecnológico para proteções daeconomia e consumidorenvolvendo dados de seuscidadãos e cidadãs.

Palavras Chave: Dados pessoais, Promoções Comerciais, Publicidade. 
ABSTRACT: This paper describes the context of digital commerce and the relevance of data to enable nowadays-economic relations; use of commercial campaigns using lotteryto marketing products and services and as data collecting tools. Having in mind the regulatory landmarks to protect Brazilian and European personal data,the Secretaria de Acompanhamento Fiscal, Energia e Loteria has potential to contribute to generate social values; authorizing commercial campaigns under the scope of protection participants data. This research study case concludes that few aspects are demanded from enterprises to avoid inappropriate use of data and the majority of it doesn't have in its campaigns rules details of its usage. The employed method is deductive-hypothetical studying the case, analyzing the national and international legislation and doctrine. Jurisprudence was not found. The results point that only three of the studied cases superficially mention how the data will be treated, other cases limit themselves to ask for authorized use of image and voice. Brazil has dispersed data protection and from 2020 and on it will also be specific on the data protection issue. The European Directive of Personal Data Protection is already operating. The main conclusion is that the proliferation of promotional campaigns to collect data, the growth of digital business body and utilization of new technology for propaganda pressure for the existence of specific legal marks however demanding public instances to enforce preventive observation, establishing a juridical administrative conductive paradigm to strength social corporative responsibility and more technological development to protect economy and consumer considering citizen data.

Key-Words: Personal data, Promotional Campaigns, Marketing

\section{SUMÁRIO: Introdução; 2. Dados moeda valiosa na internet; 3. Valores e a possibilidade de a Sefel contribuir na construção deles; 4 . Estudo de caso; 5 . Direitos da personalidade e de proteção de dados; Conclusões; Referências.}

\section{INTRODUÇÃO}

O presente texto analisa as últimas 50 promoções comerciais autorizadas sob o ponto de vista da proteção de dados de seusparticipantes. Conclui que muito pouco foi exigido das empresas para garantir que não houvesse indevido uso desses dados e que a grande maioria (47 casos) não dispõem nosseus regulamentos sobre detalhes de como serão usados os dados coletados. Diante da importância crescente dos dados para o comércio digital e do uso das promoções comerciais para coleta desses dados, esta pesquisa recomenda que a Secretaria de Acompanhamento Fiscal, Energia e Loteria passe a exigir maior comprometimento com medidas de proteção de dados, nos termos da Lei de Proteção de Dados No 13.709/2018 (BRASIL, 2018).

A Secretaria de Acompanhamento Fiscal, Energia e Loteria além de regular a loteria é responsável pela autorização das atividades de distribuição gratuita de prêmios ("promoções comerciais") realizadas por instituições financeiras e na captação antecipada de poupança popular ferramentas utilizadas como ferramenta de marketing das empresas. A distribuição gratuita de prêmios é uma "estratégia de marketing que visa alavancar a venda de produtos, serviços, promoção de marcas ou imagens" (SEFEL, 2018a) mas não pode ser usada para lavagem de dinheiro, publicidade enganosa ou abusiva ou coleta indiscriminada de dados pessoais.

Assim essas promoções comerciais, sejam mediante sorteio, vale-brinde ou concurso, com objetivo publicitário devem respeitar as normas de responsabilidade social corporativa, do Direito do Consumidor e da proteção a dados pessoais. E por isso sua realização depende de prévia autorização. "No caso de promoções comerciais realizadas por instituições financeiras, a autorização e a fiscalização dessas atividades competem à Secretaria de Acompanhamento Fiscal, 
Energia e Loteria, sucessora da Secretaria de Acompanhamento Econômico nessas atribuições. Nos demais casos, essa competência foi delegada pelo Ministério da Fazenda à Caixa Econômica Federal ou à Susep"(SEFEL, 2018a). Além disso, não precisam de autorização concurso exclusivamente artístico, cultural, desportivo ou recreativo.

O Sistema de Controle de Promoção Comercial - SCPC foi convertido em um procedimento eletrônico, desde a Portaria SEFEL no 67/2017, isso simplifica o processo de autorização e tende a contribuir para a maior lisura da oferta de prêmios. O prazo para protocolar o pedido de autorização eletronicamente é de 40 a 120 dias antes do início da promoção, mediante pagamento de uma taxa de fiscalização que é variável de acordo com o valor do prêmio (SEFEL, 2018b).

Pela análise dos casos divulgados nesse sistema eletrônico de controle, até a redação do presente texto das 271 promoções autorizadas, analisando as 50 mais recentes (Anexo 1), constatou-se que a responsabilidade pela gestão de dados dos usuários estava indicada em apenas 3 promoções, as demais apenas se limitavam a delimitar a um ano o uso da imagem ou imagem e voz de seusparticipantes.

\section{DADOS MOEDA VALIOSA NA INTERNET}

Tudo o que se faz na internet, como acessar redes sociais, ler e enviar emails, assistir vídeos, ouvir música, por mais que pareça ser gratuito tem um preço: em dados pessoais. As interações digitais geram dados anônimos ou não que podem ser vendidos às empresas como publicidade, utilizados por campanhas políticas ou coletados estatisticamente por governos. Principalmente com o crescente uso de smartphones, a informação se tornou uma moeda muito valiosa (CANALTECH, 2016). Os dados nesse contexto geram valor, como se fossem capital financeiro,possibilitando novos produtos e serviços digitais (MIT; ORACLE, 2016) em um mercado que tem um volume já significativo e crescente.

O relatório sobre o comércio eletrônico brasileiro realizado pela Ebitestima que o faturamento do varejo de bens de consumo online (e-commerce) em 2018 deverá ser de R $\$ 53,4$ bilhõeso que representa uma alta de $12 \%$ tendo em vista os números de 2017 . Se considerado além dos modelos de negócio venda de bens entre empresa e consumidor o mercado de digital brasileirojá movimentou muito mais tendo chegado aR \$112,2 bilhões em 2017(EBIT, 2018, p. 5). Nesse segundo número estão incluídas as venda de produtos novos e usados de empresas para consumidores e consumidoras (B2C) e entre consumidores e consumidoras (C2C), além de serviços (turismo, locação de veículos e Ingressos).

Nesse contexto digital o marketing passa a ser tecnológico (martech) e para que as ferramentas possam ser aplicadas tem de haver um ativo de dados considerável e consistente (GHIRALDINI, 2018) que permitam diversas estratégias como a mensuração do impacto da publicidade, o constante contato com o público alvo, a coleta sistemática de informações que o próprio consumidor ou a própria consumidora produzirem, a precisa identificação (microtagueamento) para ser possível avenda de publicidade segmentada comercializadas em leilões eletrônicos de espaços publicitários (DENNY, 2018a).

O modus operandi da interpelaçãoalgorítmica do consumidor exibe algumas especificidades: caracteriza-se pela mensurabilidade, apoiando-se em diversos tipos de métricas; envolve também a recursividade, valendo-se de informações sobre si fornecidas de alguma forma pelo próprio consumidor; desemboca no perfilamento, que consiste na definição de perfis a partir da combinação de traçosextraídos de cada um; e agrupa perfis afins em nichos, o que corresponde ao fenômeno da nichificação (DE CASTRO, 2018, p. 3). 
Em virtude de tamanha relevância essas informações de clientes devem ser tratadas como estratégicas. E portanto gerenciadas com o mesmo cuidado dedicado aos dados internos das empresas que permitem que sejam implementados por exemplo softwares de gestão que automatizam os processos e integram as atividades de áreas de vendas, finanças, contabilidade, fiscal, estoque, compras, recursos humanos, produção e logística (TOTVS, 2018), denominados Sistemas Integrados de Gestão Empresarial, mais conhecido pela sigla em inglês Enterprise Resource Planning(ERP). Dados pessoais são a mola propulsora da economia digital (DENNY, 2018a) que é muito pujante.

\section{Figura 1 - Números do comércio digital no Brasil em 2017}

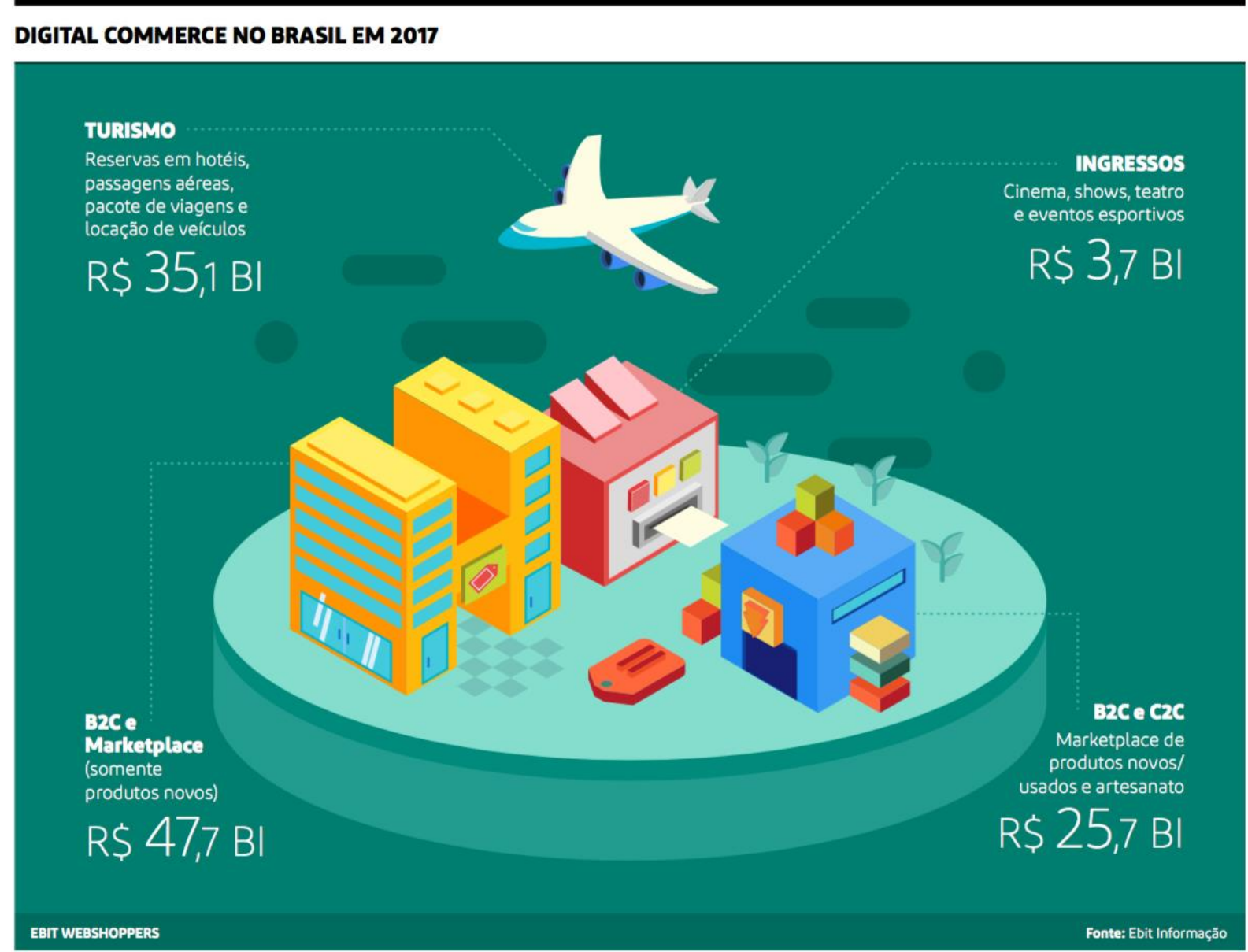

Fonte: Webshoppers (EBIT, 2018, p. 21)

Em virtude disso, as empresas com atuação digital estão em uma corrida para criar estoques exclusivos de capital de dados - e formas de usá-lo - antes que seus rivais os superem ou que as regulações arrefeçam essas possibilidades. Uma nova arquitetura de computação tem sido demandada para incluir três características principais: igualdade de dados, liquidez e segurança (data equality, liquidity, andsecurity) (MIT; ORACLE, 2016). Isso para facilitar a minimização da coleta de dados pessoais, uma adaptação orientada a dados de produtos e serviços bem como o desenvolvimento de um conjunto de serviços que são intercambiáveis, fáceis de comprar e usar, fornecidos pela Internet em serviços de nuvem pública ou com data centers corporativos reconfigurados como nuvens privadas (MIT; ORACLE, 2016).

O Regulamento Geral sobre a Proteção de Dados (GDPR, na sigla em inglês) da União Europeia(EU, 2016), entrou em vigor em 25 de maio de 2018 dispondo sobre o tratamento de dados pessoais de europeus e sobre a circulação de dados nos países da Europa. A Lei Geral de Proteção de Dados brasileira (BRASIL, 2018), muito semelhante, entrará em vigor em 2020. Ela determina 
os direitos que os cidadãos e as cidadãs do Brasilterão sobre seus dados e uma série de critérios a que, para utilizá-los, empresas e governo terão que obedecer, trazendo segurança jurídica para as atividades que dependem do uso de dados pessoais que operavam sem certeza sobre quais regras deveriam ser aplicadas (SOUZA et al., 2018).

Diante desse novo marco regulatório, cabe às instituições, desejosas de avançar na utilização de dados, regular internamente essa temática, com base nas diretrizes e limites normativos, de modo a oferecer maiores garantias e segurança. Porém, órgãos públicos devem exigir o cumprimento dessas políticas, dessa forma, a Secretaria de Acompanhamento Fiscal, Energia e Loteria tem capacidade de contribuir para que haja maior observância a esses princípios e com isso maior respeito aos dados deconsumidores participantes das promoções.

As boas práticas de governança social corporativa convertem princípios e orientações genéricos em recomendações objetivas (FILHO; BENEDICTO; CALIL, 2014). Dessa forma possibilita o alinhamento de interesses conflitantes com a finalidade de preservar e otimizar tanto a finalidade econômica como a da sociedade (EDIMUNDO, 2014).

Cabe à regulação estabelecer um marco normativo que vise a preservar o sistema (de jogos e apostas), seu uso sadio para os usuários e sua imagem perante o corpo social. Nessa linha, as formas de regulação estatal podem oferecer uma contribuição positiva para atacar esta problemática(OLIVEIRA, 2017, p. 8).

Zelar para que as promoções comerciais atendam os requisitos regulatórios de proteção de dados, bem como as expectativas sociais e corporativas é um desafio amplo. E há várias formas de atuação que aSEFELpode adotar a fim de exigir condutas responsáveis das empresas mandatárias das promoções comerciais em seu contexto social, assim contribuindo para governança socioambientalmente responsável (DENNY, 2018c) e para a implementação de sua própria responsabilidade social corporativa.

\section{VALORES E A POSSIBILIDADE DE A SEFEL CONTRIBUIR NA CONSTRUÇÃO DELES}

Como descrito na canção composta pelo artista Jorge Ben Jor e interpretada por Wilson Simonal,oimaginário social o Brasil frequentemente aparece como um "paraíso tropical abençoado por Deus" (BEN JOR;, 1969), , os meios de comunicação em obras artísticas, comerciais ou peças publicitárias exibem cenas paradisíacas quando retratam o território brasileiro. As belezas naturais do país assim como sua grandiosidade e povo hospitaleiro são parte da imagem na propagada e nas promoções desde seu descobrimento e mais difundida com o advento do século XX, desde o verdeamarelismo do integralista Plínio Salgado nos anos 1920, passando por Getúlio Vargas de 1939 a 1945 (HOLLANDA, 1989) até o século XXI. A iniciativa privada e liderançaspolíticas mantém essa associação que ainda agregam samba, carnaval e futebol. Portanto, um local de férias ou até para viver uma história ou mesmo aventura dentro de um ambiente tropical e paradisíaco para muitas pessoas mundo à fora.

O regresso para o regime democrático na década de 1980, a estabilidade da moeda, o aquecimento econômico, a diminuição da pobreza, a atratividade para empresas multinacionais, as melhorias nos indicadores sociais e passar a ser credor do FMI ao invés de devedor foram fatores que contribuíram para disseminar essa imagem do país no globo terrestre (AMORIM, 2010, p. 216).Por meio de práticas diferentes das utilizadas em países desenvolvidos a economia brasileira conseguiu diluir os danos causados pela crise econômica do biênio 2008-2009 tendo como foco investir na expansão do mercado interno com políticas contra cíclicas, não apenas exportando 
produtos para atender as requisições dos países ricos, além de aumentar suas relações, e portanto influencia, com outras nações emergentes ou subdesenvolvidas (AMORIM, 2010, p. 217).

Este momento projetou o estado-brasileiro como um futuro player importante no tabuleiro da política internacional com grande simbolismo. Entretanto, é ressalvável sua proeminência desde os anos 1990 ao conseguir galgar maiores espaços nos cenários continental e global, de modo que os governos tenham adotado a postura de dar continuidade sem grandes variações.

As diretrizes da política externa brasileira nos dois mandatos de FHC seguiram parâmetros tradicionais: o pacifismo, o respeito ao direito internacional, a defesa dos princípios de autodeterminação e não-intervenção, e o pragmatismo como instrumento necessário e eficaz à defesa dos interesses do país. Suficientemente gerais, tais princípios puderam, portanto, ser adaptados a diferentes circunstâncias ao proporcionarem aos tomadores de decisões uma flexibilidade discursiva e conceitual, facilitando, de acordo com as mudanças históricas ou conjunturais, o espaço para inserir mecanismos de adaptação a novas realidades ou a uma compreensão de mundo distinta (VIGEVANI; DE OLIVEIRA; CINTRA, 2003, p. $31)$.

Os valores trabalhados ao longo de mais de uma década para a projeção do Brasil no cenário internacional lhe renderam a imagem de um país pacifista mediador de conflitos e uma alternativa às potencias beligerantes, e também novo polo para transações econômicas.

Com as passagens indicadas acima o Brasil se tornou um líder hegemônico na América do Sul, em principal no Mercosul, e uma parte importante dos BRICS conduzindo para o aumento de seu softpower (ABBOTT; SNIDAL, 2000; KEOHANE; NYE, 1998; NASSER, 2006) tendo como demonstrações explícitas a produção dos eventos esportivos: Copa do Mundo de Futebol FIFA em 2014 e os Jogos Olímpicos em 2016, o último com atletas patrocinados e patrocinadas pela Caixa Econômica Federal. Softpower é a "habilidade de conseguir o que se quer pela atração ao invés da coerção ou pagamentos. Surge da atratividade da cultura, ideais políticos e políticas de um país" (NYE JR, 2004, p. X).

Esse softpower de um país está posicionado em três esferas: valores políticos, quando empregados em seu território nacional e em terras estrangeiras; políticas internacionais, quando respeitadas por sua autoridade moral; e legitimidade e valores culturais, nos locais em que são atrativos.

Ao investir em esporte como uma ferramenta de mobilização social, ainda mais por ser um país emergente, o Brasil manda uma mensagem de esperança em principal para outros estadosnações e seus próprios cidadãos.

A projeção de um país em um momento de sucesso e a estabilidade econômica garantindo a possibilidade de ascensão de classe social transmitem ao brasileiro esperanças, porém os sonhos que podem ser obtidos por um vencedor dos prêmios das loterias da Caixa transmitem não apenas a possibilidade de pagar dívidas em tempos de crise econômica, mas também de vivenciar fantasias como os personagens de grandes eventos esportivos e outros círculos sociais.

Um Olimpo de vedetes domina a cultura de massa, mas se comunica, pela cultura de massa, com a humanidade corrente. Os olimpianos, por meio de sua dupla natureza, divina e humana, efetuam a circulação permanente entre o mundo da projeção e o mundo da identificação. Eles realizam os fantasmas que os mortais não podem realizar, mas chamam os mortais para realizar o imaginário. [...] Assim, uma nova alta sociedade, mais mitológica do que as antigas altas sociedades burguesas ou aristocráticas, mas, paradoxalmente mais próxima da humanidade quotidiana, é constituída pela nova camada olimpiana. Os olimpianos estão presentes em todos os setores da cultura de massa. Heróis do imaginário cinematográfico, são também os heróis da informação vedetizada. Estão presentes nos pontos de contato entre a 
cultura de massa e o público: entrevistas, festas de caridade, exibições publicitárias, programas televisados e radiofônicos. [...] ( MORIN, 1997, p. 107).

As Loterias proporcionam a mobilidade social perseguida por muitos brasileiros e brasileiras, criar umanovapersonagem de si em uma diferente narrativa ainda mais dentro de um cenário com 13 milhões de desempregados, ou seja, para muitos e muitas significa no mínimo uma condição mínima para o ser humano: dignidade. Outro fator é o rompimento com a coerção social ao buscar um padrão de vida melhor e não aceitar as condições nas quais se encontra assim como seus pares.

Entende-se que coerção social, é a força que obriga os sujeitos a conformarem-se às regras impostas pela sociedade na vida cotidiana independentemente das suas escolhas. Tal força manifesta-se pela política em princípio, de maneira espontânea transmitida de gerações para gerações, fazendo com que o indivíduo tenha determinadas práticas sócias e politicas naturalmente. Aquele que por alguma razão não o fizer, estará sujeito a ser excluído ou discriminado dentro do seu grupo, por não enquadrar-se aos padrões que a própria sociedade determinou. (DURKHEIM, 2007)

Corroborando o pensamento de coerção social há o crescente narcisismo da era moderna, fruto da insegurança oriunda do esvaziamento de valores e sentidos (LASCH, 1986). Tais sensações podem conduzir no individuo um crescente vácuo de seus anseios, esperanças e sonhos, os quais buscará preenche-los em personalidades externas, ao invés de focar em si, por outro lado a ascensão social pode ajudar a responder certos questionamentos e sugerir outros para mais rupturas de padrões e conceitos do indivíduo como visto na ascensão de classe social em governos recentes prévios à recessão, portanto, tal premiação pode influenciar nesta mobilização assim como em questões de fundo psicológico e de auto estima.

O prêmio pode garantir uma sensação de segurança mais duradoura, já que o vencedor ou vencedora não "depende" diretamente de agentes políticos ou empresariais e sim de sua "sorte" ainda mais em tempos de alta volubilidade em política e economia.

Líquido-moderna é uma sociedade em que as condições sob as quais seus membros agem mudam num tempo mais curto do que aquele necessário para a consolidação, em hábitos e rotinas, das formas de agir. A liquidez da vida e da sociedade se alimentam e se revigoram mutuamente (BAUMAN, 2007, p. 7).

Em 1968, a preconização da Sociedade do Espetáculo (DEBORD, 1997) apontava os veículos de comunicação como os grandes mediadores de relações humanas o que têm se confirmado com os avanços dos próprios meios e em principal da globalização. Seja em cenários de crise ou de abundância a população brasileira tende a acreditar no que é transmitido no meios de comunicação, espaço nos quais a Caixa Econômica Federal e as Loterias se fazem presentes, entrando assim para o meio destas pessoas e conquistando credibilidade.

"O produto é o que a empresa fabrica; o consumidor acaba comprando a marca" (TORQUATO, 2010, P. 104). O nome da empresa é duradouro, está no cotidiano das pessoas e conduzida de forma prudente em tempos de crise segue com o seu público e o vindouro, portanto gerando assim ainda maior respeito. Verdadeiras potências além de seus produtos com poder de influenciar na vida das pessoas e sociedades (KLEIN, 2002).

"É fundamental, portanto, intensificar os meios e recursos para proteger a marca. Uma marca não tem preço" (TORQUATO, 2010, p. 115). Sendo assim, a manutenção dos nomes “Caixa 
Econômica Federal" e da palavra "loteria" é feita com considerável atenção e distanciada de escândalos ou mesmo de jogatina ilegal como cassinos e jogo do bicho.

As marcas estão sujeitas à opinião pública "que funciona como salvaguarda da sociedade, é de suas criações mais importantes para o próprio desenvolvimento e ajuste social" (TORQUATO, 2010, p. 83) e o público refuta atividades corruptas entre outras más práticas. A opinião pública é gerida por ideias e crenças pessoais aglomeradas em núcleos que se expandem de maneira vertical entre as classes sociais e horizontal nos espaços geográficos sendo conduzidas por meios de comunicação, e estes ressoam os fatos sendo afetados por circunstâncias, complexidade dos fatos, peculiaridades dos atores sociais e características espaciais e temporais (TORQUATO, 2010, p. $83)$.

A opinião pública é determinada por aspectos de ordem psicológica, sociológica e histórica (TORQUATO, 2010, p. 83). As prerrogativas psicológicas têm em sua base atitudes pessoais e grupais, crenças e ideologias que atravessam os campos racionais e emocionais capazes de apelar para uma base presente nos seres humanos nas quais estão alojadas e arquivadas suas crenças, valores, estereótipos, princípios e também suas propensões de refutar ou aceitar diferentes crenças, comportamentos, valores e culturas. Por sua vez, estes conjuntos se amalgamam no inconsciente e consciente do home realizando exercícios de interpretação, percepção e avaliação de pessoas e eventos (TORQUATO, 2010, p. 83). Ou seja, a vivência da pessoa assim como sua visão do mundo ao seu entorno, o tempo em que vive e o espaço geográfico no qual está inserida influenciam como aceitará os cenários, situações e personagens. Desta forma como a questão de apostar na Loteria assim como confiar e respeitar na instituição que a rege.

"O símbolo é representação que evoca, instantaneamente, uma ideia ou uma doutrina, o sinal automático que sugestiona as pessoas, integrando-as em torno de uma causa" (TCHAKHOTINE, 1967, apud TORQUATO, 2010, p. 103). Sendo assim, símbolos entram nas vidas das pessoas e necessitam de trabalho e respeito de ambas partes para permanecerem.

Os veículos nos quais os sorteios de loteria são apresentados no fim do ano assim como também a divulgação de resultados devem ser levados em consideração, principalmente em relação ao fator credibilidade, é prudente considerar os pesos relativos quanto à mensagens e veículos, estes também possuem suas marcas, e como esses pesos e impactos interagem com a população (TORQUATO, 2010, p. 100).

O marketing social tem sua ótica voltada para a criação de elos com diferentes grupos sociais e estes em sequência desenvolvem mecanismos de defesa abstraindo-se da posição de mero consumidor de bens e serviços e convertendo-se em núcleos ativos e engajados nos processos de decisão da vida pública e privada levando a questionamentos, refutações, denúncias e busca por maiores condições de cidadania (TORQUATO, 2010, p. 81).

Os rumos do capitalismo possuem forte influencia nas mudanças da história do marketing. $\mathrm{Na}$ era industrial os produtos das fábricas eram vendidos diretamente paraconsumidores surgindo o "fordismo" baseado na padronização e crescimento em escala. Como apontado pelo magnata dos automóveis Henry Ford: "o carro pode ser de qualquer cor desde que seja preto", esta é uma das melhores frases para definir o "marketing 1.0", ou seja, quando o marketing era centrado no produto (KOTLER, 2010, p. 4).

O advento da globalização abriu as portas para a era da informação, agentes sociais passaram possuir informações, sendo assim, elevando sua importância no panorama e habilitando o consumidor a ter melhores condições de avaliar e escolher produtos, uma evolução em comparação ao período prévio. O marketing avança para a segmentação de mercado e desenvolvimento de produtos focados em um mercado-alvo definido com padrões superiores, em consequência aqueles que consomemsãomais assediados por uma variedade maior de empresas. $\mathrm{O}$ ponto negativo é ter o cliente sendo alvo passivo de sorrateiras campanhas de marketing. Adentra a fase "marketing 2.0" (KOTLER, 2010, p. 4). 
Os dois períodos mencionados acima possibilitaram a entrada do "marketing 3.0", quando as campanhas de marketing começam a tratar os possíveis compradores além do estereotipo do consumidor tendo os profissionais de marketing observando-os como seres humanos em sua plenitude formados por mente, espírito e coração em busca de respostas para seus anseios de transformar o mundo globalizado, junto de seus problemas, em um ambiente aperfeiçoado iniciando por suas comunidades. Imersos em um mundo segregado e confuso, os consumidores e as consumidoras encontram seus anseios nas empresas que tratem de suas necessidades como justiça social, ambiental e econômica em sua missão, valores e visão. $\mathrm{O}$ consumidor e a consumidora atual não sãosaciados apenas por satisfação funcional ou emocional, mas algo mais elevado e até espiritual de caráter abstrato e subjetivo inserido nos produtos e serviços (KOTLER, 2010, p. 4).

Ao dialogar com o público alvo, o marketing 3.0 inverte os valores dos estágios anteriores fomentando a obrigação moral das empresas em contribuir em termos de visões e valores e apresenta-los à sociedade sua busca e seu objetivo para encontrar soluções para problemas sociais. Ações de cidadania, responsabilidade social, sustentabilidade e envolvimento da empresa com a comunidade na qual está inserida são alguns dos exemplos destas medidas.

Com este panorama é visível que as campanhas da Caixa Econômica Federal apresentam um perfil com humor leve para interagir com uma faixa de público maior e ao mesmo tempo seguindo as tendências contemporâneas como a linguagem de internet e memes assim como também a disposição do público brasileiro para o humor. A adição da apresentadora Titi Müller vai de encontro com as campanhas mundiais de valorização da figura feminina assim como a própria personagem.

Por outro lado, o patrocínio de atletas e centros esportivos denota atenção e cuidado não apenas para o esporte brasileiro, mas para a juventude do país e a formação de melhores cidadãos e cidadãs como um todo. Com as campanhas e a reversão de recursos para patrocinar atletas, comunidades e centros de treinamento a Caixa Econômica Federal aponta um cuidado para valores de cidadania e responsabilidade social em busca de solução para dilemas contemporâneos ainda mais em uma sociedade usurpada de seu potencial máximo pela desigualdade social e demais males.

Essa postura segue a de demais empresas públicas e privadas, nacionais e multinacionais que investem com foco em imagem e reputação para as demandas mais fortes dos grupos sociais fortalecendo elos com as comunidades e suas necessidades, pois assim nasceu o marketing social (TORQUATO, 2010, p.81). Há de ser considerado que pelo apelo da nação, empresas nacionais não possuem seu reconhecimento apenas dentro das próprias fronteiras, portanto há um cuidado maior em zelar pelo próprio nome.

Na época da globalização, alteram-se quantitativa e qualitativamente as formas de sociabilidade e os jogos das forças sociais, no âmbito de uma configuração histórico-social da vida, trabalho e cultura na qual as sociedades civis nacionais se revelam províncias da sociedade civil mundial em formação. Nessa época, as tecnologias eletrônicas, informáticas e cibernéticas impregnam crescente e generalizadamente todas as esferas da sociedade nacional e mundial; e de modo particularmente acentuado as estruturas de poder, as tecnoestruturas, os thinktanks, os lobbies, as organizações multilaterais e as corporações transnacionais, sem esquecer as corporações da mídia. Esse pode ser o clima em que se forma, impõe e sobrepõe O príncipe eletrônico, sem o qual seria difícil compreender a teoria e a prática da política na época da globalização. (IANNI, 2003, p. 143).

Um mundo globalizado apresenta novas oportunidades para uma marca como mostrar a eficiência em seu território e o seu apelo junto ao público. A mente humana opera com conceitos, sendo assim, ao ser informada do nome de uma empresa sua atenção seletiva organiza uma 
filtragem para aceitar ou rejeitar estabelecida e estabelecendo conceitos partindo de comparações relacionando produtos, marcas e por fim construindo imagens (TORQUATO, 2010, p. 105).

Sendo parte do governo federal dentro de um mundo globalizado a Caixa Econômica Federal pode ser vista como uma ferramenta de seu softpower, ou seja, um instrumento para a propagação da marca do Estado brasileiro para além de suas fronteiras. Uma equipe esportiva faz parte do softpower cultural do país, uma vez que leva a bandeira e os valores nacionais para competições no exterior, dentre elas Os Jogos Olímpicos. Esta é uma maneira de fazer com que estrangeiros entre em contato com os valores e mensagens da Caixa Econômica Federal.

O Brasil se classificou no $29^{\circ}$ posto do ranking Portland Softpower $30^{1}, 19^{\circ}$ no Monocle ${ }^{2}$, entretanto não há país latino-americano de maior expressão que o Brasil nestas listas, sendo assim o de maior projeção entre seus semelhantes em termos de região e cultura, porém distante das potencias mundiais. Justificando ainda mais o trabalho feito com atletas assim como pagar justamente seus prêmios e evitar ter o nome da Caixa Econômica Federal vinculado aos escândalos de corrupção que assolam o país e repercutem em veículos estrangeiros.

Com esta postura a Caixa Econômica Federal atende aos preceitos do marketing 3.0 encontrando os valores de seus consumidores e consumidorasalém deapontarpara a agenda seguida por empresas de projeção social e ainda servindo como uma importante ferramenta na propagação dos ideais brasileiros para o mundo. Estes aspectos de responsabilidade social ajudam na regulação das Loterias.

Como denotado acima a manutenção de uma marca e seu nome é muito importante para sua sobrevivência e também prosperidade, portanto são despendidos esforços em sua defesa (ROBERTS; DOWLING, 2002). Apresentar para a sociedade as condições nas quais os negócios e atividades eram feitos, as práticas e seus agentes e se necessário explicar que não fosse de tal maneira nada seria produzido é um processo inicial para a conquista da confiança do público alvo (CASTRO, 2015, p. 10). Estes métodos são os mais prudentes quando ocorrem casos de corrupção e uso indevido de dados coletados dos cidadãos e das cidadãs do Brasil.

Em tempos de divulgação sistemática de conteúdo falso, incongruente ou irrelevante (EASA, 2018), é importante considerar para quais veículos fazer estas revelações escolhendo dentre aqueles que possuem aderência e respeitabilidade junto ao público. Aparições midiáticas em demasia levam ao processo de superexposição conduzindo ao desgaste da marca, produtos e seus agentes (SCHWARTZENBERG, 1977, p. 217), portanto denuncias de corrupção, usos indevidos de dados coletados somados aos riscos de desinformação podem iniciar ou agravar o processo de erosão da reputação (DOORLEY; GARCIA, 2015) de uma empresa.

Os danos à reputação são uma das principais preocupações de executivos e as marcas que representam ainda mais na realidade brasileira de instabilidade econômica passando por mudanças legislativas, regulatórias e sociais. Para seguir relevante neste contexto é recomendável adotar práticas de compliance, ética e comunicação clara e efetiva (CASTRO, 2015, p. 10). Com uma aproximação midiática saudável e maiores processos de regulação das Loterias o impacto desta empresa pública na vida debrasileiros e brasileiras será de uma maneira positiva e seu apelo internacional junto ao softpower brasileiro crescerá.

\section{ESTUDO DE CASO}

A presente monografia se dispôs a analisar os regulamentos das últimas 50 promoções comerciais, das 271 promoções autorizadas e disponíveis no Sistema de Controle de Promoção Comercial (SEFEL, 2018b). O recorte temático foram as disposições contratuais a respeito da

${ }^{1}$ https://softpower30.com/ Acessado 10/10/2018 às 17h07.

2https://monocle.com/film/affairs/soft-power-survey-2016-17/ Acessado 11/10/2018 às 17h16.

Revista de Direito Brasileira | Florianópolis, SC | v. 23 | n. 9 | p.302-322 | Mai./Ago. 2019 
proteção de dados dos participantes. Constatou que a responsabilidade pela gestão de dados deusuários e usuárias estava indicada em apenas 3 promoções nos seguintes termos:

\section{MASTERCARD AMIGOS PELO MUNDO - SICREDI 05.577.343/0001-37 - MASTERCARD BRASIL04.000560/2018 \\ 19/10/2018a22/01/2019}

Os participantes autorizam, no ato do cadastro na Promoção, a utilização de seu e-mail, telefones e demais dados informados com o propósito de formação e atualização de cadastro, reforço de mídiapublicitária e divulgação da própriaPromoção, entrega do Prêmio e/ou a experiência de uso do Prêmio, em todo o território nacional, nos limites do Código de Defesa do Consumidor, sem nenhum ônus para a Promotora, sendo que, no entanto, de acordo com o que dispõe o Artigo 11 da Portaria MF no 41/2008, a Promotora está expressamente vedada de comercializar ou ceder, ainda que a título gratuito, os dados coletados nesta Promoção. Os participantes contemplados autorizam ainda a utilização de seus endereçosfísicos para operacionalizar a comunicação do resultado da Promoção, bem como a entrega do prêmio e sua fruição.

Ao término da Promoção, todos os participantes que não forem cadastrados no Programa Mastercard ${ }^{\circledR}$ Surpreenda, poderão ser convidados a participar do programa de benefícios da Promotora por meio dos dados informados nesta Promoção.

Os dados e informações coletados estarão armazenados em ambiente seguro, observado o estado da técnicadisponível, e somente poderão ser acessados por pessoas qualificadas e previamente autorizadas, em observância à legislação em vigor.

As Promotoras nãoserãoresponsáveis por problemas, falhas ou funcionamento técnico do participante, de qualquer tipo, em redes de computadores, servidores ou provedores do participante, equipamentos de computadores, celulares, tablets, hardware ou software do participante, ou erro, interrupção, defeito, atraso ou falha em operações ou transmissões nos sistemas do participante para o correto processamento de inscrições, incluindo, mas não se limitando a transmissão imprecisa de cadastros, em razão de problemas técnicos, congestionamento na Internet, vírus, falha de programação (bugs) ou violação por terceiros (hackers).

As Promotoras não se responsabilizam pela autenticidade dos dados fornecidos pelos participantes.

679 Mastercard Amigos pelo Mundo05.577.343/0001-37 - MASTERCARD BRASIL $\quad 04.000559 / 201 \quad 19 / 10 / 2018 \mathrm{a} 22 / 01 / 2019$

Os participantes autorizam, no ato do cadastro na Promoção, a utilização de seu e-mail, telefones e demais dados informados com o propósito de formação e atualização de cadastro, reforço de mídiapublicitária e divulgação da própriaPromoção, entrega do Prêmio e/ou a experiência de uso do Prêmio, em todo o território nacional, nos limites do Código de Defesa do Consumidor, sem nenhum ônus para a Promotora, sendo que, no entanto, de acordo com o que dispõe o Artigo 11 da Portaria MF no 41/2008, a Promotora está expressamente vedada de comercializar ou ceder, ainda que a título gratuito, os dados coletados nesta Promoção. Os participantes contemplados autorizam ainda a utilização de seus endereçosfísicos para operacionalizar a comunicação do resultado da Promoção, bem como a entrega do prêmio e sua fruição.

Ao término da Promoção, todos os participantes que não forem cadastrados no Programa Mastercard® Surpreenda, poderão ser convidados a participar do programa de benefícios da Promotora por meio dos dados informados nesta Promoção. 
Os dados e informações coletados estarão armazenados em ambiente seguro, observado o estado da técnicadisponível, e somente poderão ser acessados por pessoas qualificadas e previamente autorizadas, em observância à legislação em vigor.

A Promotora nãoserá responsável por problemas, falhas ou funcionamento técnico do participante, de qualquer tipo, em redes de computadores, servidores ou provedores do participante, equipamentos de computadores, celulares, tablets, hardware ou software do participante, ou erro, interrupção, defeito, atraso ou falha em operações ou transmissões nos sistemas do participante para o correto processamento de inscrições, incluindo, mas não se limitando a transmissão imprecisa de cadastros, em razão de problemas técnicos, congestionamento na Internet, vírus, falha de programação (bugs) ou violação por terceiros (hackers).

A Promotora não se responsabiliza pela autenticidade dos dados fornecidos pelos participantes.

\section{CAMPANHA SORTE NA GARAGEM IV SPC SERVICO DE PROTECAO AO CREDITO $13.608 .948 / 0001-76 \quad-$ $06.000549 / 2018$ $15 / 10 / 2018 \mathrm{a} 09 / 01 / 2019$}

Caso seja de interesse da Requerente/Mandatária e/ou das Aderentes utilizar a imagem dos contemplados para fins de divulgação da presente campanha, poderão fazê-lo, pelo período de até 12 doze meses, sob fiel obediência aos comandos contidos no Inciso XXV do Anexo III da Portaria MF no 41, de 2008.Os ganhadores autorizam, desde já, como consequência da conquista dos prêmios, a utilização de seus nomes, imagens e sons de voz, em qualquer um dos meios escolhidos pela Requerente/Mandatária e/ou pelas Aderentes, para divulgação desta campanha, pelo período de 1 (um) ano contado da data da respectiva apuração e assim como os demais participantes autorizam, também, a utilização de seus dados, como endereçofísico, eletrônico, telefone e demais dados constantes do cupom/cadastro, desde que não fira o Código de Defesa do Consumidor, com o propósito de formação e/ou atualização de cadastro da Requerente/Mandatária e/ou pelas Aderentes, reforço de mídiapublicitária e divulgação, sem nenhum ônus para estas, sendo certo, porém, o comprometimento da nãocomercialização ou cessão dos dados a terceiro, ainda que a título gratuito.

Em uma das promoções apesar de não estar previsto quais dados serão coletados por quanto tempo, está previsto o afastamento da responsabilidade da promotora caso dados perdidos por falhas de funcionamento técnico ou de invasão de dispositivo eletrônico por terceiros

\section{SUPER BOWL LIII COM ITAÚ PERSONALITÉ E VISA 31.551.765/0001-43 - VISA DO BRASIL EMPREENDIMENTOS LTDA 04.000528/201827/09/2018a20/12/2018}

Em momento algum, poderão as Empresas Promotoras serem responsabilizadas por cadastros perdidos, atrasados, enviados erroneamente, incompletos, incorretos, inválidos ou imprecisos. As Empresas Promotoras nãoserãoresponsáveis por problemas, falhas ou funcionamento técnico, de qualquer tipo, em redes de computadores, servidores ou provedores, equipamentos de computadores, hardware ou software, erro, interrupção, defeito, atraso ou falha em operações ou transmissões para o correto processamento de cadastros, em razão de problemas técnicos, congestionamento na Internet, vírus, falha de programação (bugs) ou violação por terceiros (hackers), dos quais não detenha qualquer controle. Tais falhas não implicam em qualquer tipo de obrigação por parte das Empresas Promotoras e aderente em prorrogar o Período de Participação. A divulgação da imagem dos contemplados poderá ser feita até um ano após a apuração da promoção comercial 
Nas demais promoções comerciais há apenas o intuito de licenciar o uso só da imagem, da imagem e da voz, ou do nome da imagem e da voz. Esta pesquisa dividiu em dois tipos portanto: a cláusula mínima como aquela que apenas trata da imagem e as intermediárias que trazem alguma especificação também sobre nome e voz. São exemplos dessas cláusulas:

\section{Mínima}

669 QUEM GANHA FICA 31.551.765/0001-43 - VISA DO BRASIL EMPREENDIMENTOS LTDA $\quad$ 03.000548/201811/10/2018a15/10/2018

A divulgação da imagem dos contemplados poderá ser feita até um ano após a apuração da promoção comercial;

\section{Intermediária}

665 VOCÊ NO SUPER BOWL LIII 31.551.765/0001-43 - VISA DO BRASIL EMPREENDIMENTOS LTDA $\quad 04.000544 / 201808 / 10 / 2018 \mathrm{a} 20 / 12 / 2018$

O Participante contemplado autoriza, em caráterirrevogável e irretratável, a utilização de seu nome, imagem e voz para divulgação desta Promoção na mídia impressa, televisiva, radiofônica e/ou eletrônica, pelo prazo de 01 (um) ano, contado a partir do sorteio, sem qualquer tipo de ônus para as Empresas Promotoras.

Essas cláusulas mínimas e intermediárias além de serem omissas com relação à proteção de dados, também no tocante ao licenciamento dos direitos da personalidade também são omissos sobre vários aspectos desse uso determinado etemporário, deveriam especificar, finalidade, condições do uso, duração, formas de exposição, remuneração, possibilidade de renovação, e demais circunstâncias que compõem o conteúdo do negócio. Se esses termos não estiverem no contrato interpreta-se restritivamente, ou seja, ficam proibidos outros usos não expressos no contrato pois a pessoa tem de escolher as ocasiões e os modos pelos quais quer aparecer em público (BITTAR, 2015).

Se eventualmente qualquer dessas cláusulas for levada ao judiciário haverá condenação da promotora e das empresas aderentes da promoção comercial e dar ganho de causa ao participante que teve seus direitos da personalidade utilizados sem a sua expressa autorização. Contudo não se deve esperar a judicialização. A SEFEL tem meios de exigir essa adequação preventivamente garantindo assim o melhor atendimento aos preceitos legais.

Nesse sentido, o estudo de caso demonstrou que a SEFEL tem a possibilidade de contribuir para que as empresas avancem tanto com relação ao cumprimento das regras de proteção de dados como das relativas aos direitos da personalidade. Mais comprometimento pode ser exigido no momento da análise dos regulamentossubmetidos pelas empresas requerentes. Contribuindo assim para que não haja indevido uso dos dados coletados pelas empresas promotoras nem das imagens e vozes dos/das participantes.

\section{DIREITOS DA PERSONALIDADE E DE PROTEÇÃO DE DADOS}

Com o desenvolvimento das tecnologias cibernéticas e o crescimento das redes digitais ocorre simultaneamente o estabelecimento de um mercado de coleta e venda de dados pessoais, chamado "mercado de dados" (SILVEIRA, 2017)que entra em disputa com a privacidade dos indivíduos. Privacidade é um dos direitos da personalidade, assim como o é o direito ao nome, à voz e imagem. Mas nas promoções comerciais estudadas nesta monografia somente três trouxeram disposições a respeito de dados ao passo que a todas abordaram direito de imagem. 
Porém quaisquer dos direitos da personalidade são inerentes, inatos à pessoa, essenciais ao seu desenvolvimento e para a existência digna (BITTAR, 2015) e por isso são irrenunciáveis e intransmissíveis (nem o titular pode dispor livremente, autorizações de uso são permitidas apenas relativas ao aspecto patrimonial, não moral). Têm portanto características de Direito Público, como direitos fundamentais e de Direito Privado, pois se permite comercializar autorizações de uso dos aspectos patrimoniais(BARROSO, 2004).

Os direitos da personalidade são de três tipos: a) direitos físicos(à vida, integridade física, ao corpo, à imagem e à voz); b) direitos psíquicos(à liberdade de expressão, pensamento, culto, à intimidade, privacidade, reserva, integridade psíquicae sigilo, inclusive profissional); e c) de cunho moral (intimidade, nomes e outros sinais individualizadores, honra, reputação social, respeito, dignidade e o decoro) (BITTAR, 2015; DENNY, 2018b). Todos os tipos tem bases jurídicas na Constituição Federal e no Código Civil nos seguintes termos:

Na Constituição Federal

Art. $5^{\circ} \mathrm{CF}$ Todos são iguais perante a lei, sem distinção de qualquer natureza, garantindo-se aos brasileiros e aos estrangeiros residentes no País a inviolabilidade do direito à vida, à liberdade, à igualdade, à segurança e à propriedade, nos termos seguintes: (...)

IV - é livre a manifestação do pensamento, sendo vedado o anonimato;

$\mathrm{V}$ - é assegurado o direito de resposta, proporcional ao agravo, além da indenização por dano material, moral ou à imagem;

VI - é inviolável a liberdade de consciência e de crença, sendo assegurado o livre exercício dos cultos religiosos e garantida, na forma da lei, a proteção aos locais de culto e a suas liturgias; (...)

IX - é livre a expressão da atividade intelectual, artística, científica e de comunicação, independentemente de censura ou licença;

$\mathrm{X}$ - são invioláveis a intimidade, a vida privada, a honra e a imagem das pessoas, assegurado o direito a indenização pelo dano material ou moral decorrente de sua violação; (...)

XII - é inviolável o sigilo da correspondência e das comunicações telegráficas, de dados e das comunicações telefônicas, salvo, no último caso, por ordem judicial, nas hipóteses e na forma que a lei estabelecer para fins de investigação criminal ou instrução processual penal; $\quad$ (Vide Lei $n^{\circ}$ 9.296, de 1996) (...)

XIV - é assegurado a todos o acesso à informação e resguardado o sigilo da fonte, quando necessário ao exercício profissional;(...)

XXVIII - são assegurados, nos termos da lei:

a) a proteção às participações individuais em obras coletivas e à reprodução da imagem e voz humanas, inclusive nas atividades desportivas;

b) o direito de fiscalização do aproveitamento econômico das obras que criarem ou de que participarem aos criadores, aos intérpretes e às respectivas representações sindicais e associativas;

XXIX - a lei assegurará aos autores de inventos industriais privilégio temporário para sua utilização, bem como proteção às criações industriais, à propriedade das marcas, aos nomes de empresas e a outros signos distintivos, tendo em vista o interesse social e o desenvolvimento tecnológico e econômico do País (CF, 1988)

No Código Civil

CAPÍTULO II

DOS DIREITOS DA PERSONALIDADE

Art. 11. Com exceção dos casos previstos em lei, os direitos da personalidade são intransmissíveis e irrenunciáveis, não podendo o seu exercício sofrer limitação voluntária.

Art. 12. Pode-se exigir que cesse a ameaça, ou a lesão, a direito da personalidade, e reclamar perdas e danos, sem prejuízo de outras sanções previstas em lei. (...) 
Art. 16. Toda pessoa tem direito ao nome, nele compreendidos o prenome e o sobrenome.

Art. 17. O nome da pessoa não pode ser empregado por outrem em publicações ou representações que a exponham ao desprezo público, ainda quando não haja intenção difamatória.

Art. 18. Sem autorização, não se pode usar o nome alheio em propaganda comercial.

Art. 19. O pseudônimo adotado para atividades lícitas goza da proteção que se dá ao nome.

Art. 20. Salvo se autorizadas, ou se necessárias à administração da justiça ou à manutenção da ordem pública, a divulgação de escritos, a transmissão da palavra, ou a publicação, a exposição ou a utilização da imagem de uma pessoa poderão ser proibidas, a seu requerimento e sem prejuízo da indenização que couber, se lhe atingirem a honra, a boa fama ou a respeitabilidade, ou se se destinarem a fins comerciais (...)

Art. 21. A vida privada da pessoa natural é inviolável, e o juiz, a requerimento do interessado, adotará as providências necessárias para impedir ou fazer cessar ato contrário a esta norma(BRASIL, 2002)

Conforme se verifica desses dispositivos, há limites às próprias ações dos/das titulares dos direitos de personalidade que não podem transmiti-los a ninguém, apenas autorizar o uso por terceiros, mediante autorização expressa. São irrenunciáveis, não se pode abrir mão deles, apenas dispor mediante licença de uso. Que são contratos determinadosetemporários, para um uso específico e por um prazo, devendo especificar: finalidade, condições do uso, duração, formas de exposição, remuneração, possibilidade de renovaçãoe demais circunstâncias que compõem o conteúdo do negócio(DINIZ, 2017). Consequentemente se não estiver expresso no contrato o juiz interpretará restritivamente(NERY; JUNIOR, 2017), ou seja, ficam proibidos outros usos omissos no contrato pois a pessoa tem o direito de escolher em que condições permite o uso.

A proteção de dados é incluída na tipificação de direitos da personalidade como direitos psíquicos, que protegem a intimidade, privacidade e reserva. Inclui dados pessoais, recordações pessoais, memórias, diários, relações familiares, vida amorosa ou conjugal, saúde (física e mental), afeições, escolhas de entretenimento, costumes domésticos (BITTAR, 2015). Esse universo de dados está cada vez maior com a massifcação do acesso às máquinas computacionais e o barateamento da tecnologia necessária para a coleta e o armazenamento de dados.

Sistemas eletrônicos produzem, constantemente, uma enorme quantidade de dados. Com o crescente número de pontos de contato entre o mundo físico e o virtual, praticamente toda atividade humana gera um fuxo discreto de dados que pode ser reconstruído posteriormente conforme a demanda. A criação de metadados ocorre em todos os momentos do dia normal da vida em sociedade: nas relações sociais mediadas eletronicamente, nas transações comerciais ou, até mesmo, no simples ato de andar pela rua - afinal, um smartphone típico, constantemente, envia os dados de geolocalização do usuário para o fabricante $\mathrm{e}$ outras empresas (NETO; MORAIS; BEZERRA, 2018, p. 188).

Com essa multiplicação de pontos de criação, coleta e armazenamento de dados, quase tudo o que se faz pode eventualmente gerar um fluxo de dados. Os técnicos e técnicas especialistas em big data dividem em três tipos principais:a) dados concretos, estruturados, que podem ser organizados, para análise sistemática em uma planilha por exemplo; b) dados não estruturados, mais difíceis de analisar de maneira automatizada, como as postagens em mídias sociais e os documentos colocados on-line; e c) dados coletados por sensores digitais que captam ações humanas, como medidores elétricos ou imagens de satélite. 
Todos esses dados são coletados e amostrados "sem uma intenção explícita de que se tirem conclusões a partir deles" (LETOUZÉ, 2018, p. 5) por isso são designados big data (independentemente do volume ou tamanho portanto).Essa criação, coleta e armazenamento de dados tem o potencial de retirar do indivíduo o seu controle sobre seus direitos da personalidade. Contrariando assim as disposições constitucionais e legais a respeito.

A regulamentação estatal do mercado de promoções comerciais pode contribuir portanto neste ponto, fazendo com que a aplicação da lei 5.768/1971 (BRASIL, 1971) seja mais adequada a esse novo ambiente digital. No Brasil, este poder regulamentar cabe à SEFEL que por meio de autorização, fiscalização, normatização e homologação das atividades pode induzir o mercado a praticar uma política de proteção de dados pessoais mais efetiva e transparente. Fazendo assim com que sejam compartilhados com a sociedade os benefícios do uso das promoções comerciais como estratégia de marketing e de coleta de dados para "alavancar a venda de produtos, serviços, promoção de marcas ou imagens" (SEFEL, 2018a).Ainda que o poder regulamentar da SEFEL não possa inovar na ordem jurídica, há muito a ser feito dentro dos limites das leis já em vigor ou em vacatio legis.

A Lei Geral de Proteção de Dados brasileira (BRASIL, 2018), está em vacatio legis, entrará em vigor em 15 de fevereiro de 2020. Guarda muita semelhança com o GDPR da União Europeia (EU, 2016), que entrou em vigor em 25 de maio de 2018 dispondo sobre o tratamento de dados pessoais de europeus e sobre a circulação de dados nos países da Europa. Portanto impactando também os fluxos de dados aqui no Brasil.

A nossa lei vai diferenciar em três tipos: dados sensíveis que gozarão da maior proteção, dados pessoais as informações relacionadas à pessoa natural identificada ou identificável e dados anônimos commenos garantias, uma vez que, não serão capazes de identificaras pessoas aos quais se referem.

Art. $5^{\circ}$ Para os fins desta Lei, considera-se:

I - dado pessoal: informação relacionada a pessoa natural identificada ou identificável;

II - dado pessoal sensível: dado pessoal sobre origem racial ou étnica, convicção religiosa, opinião política, filiação a sindicato ou a organização de caráter religioso, filosófico ou político, dado referente à saúde ou à vida sexual, dado genético ou biométrico, quando vinculado a uma pessoa natural;

III - dado anonimizado: dado relativo a titular que não possa ser identificado, considerando a utilização de meios técnicos razoáveis e disponíveis na ocasião de seu tratamento (BRASIL, 2018)

A capacidade técnica da anonimização é discutida por alguns teóricos na medida em que podem indiretamente gerar efeitos jurídicos indiretos, como lesão ao direito à igualdade, quando do processamento desses dados pelas instituições públicas e privadas (NETO; MORAIS; BEZERRA, 2018). De qualquer forma, essa discussão não é tão importante para a presente monografia, pois os dados normalmente recolhidos com as promoções comerciais são ou dado pessoal ou dado pessoal sensível. Ambos precisam de autorização expressa e de política de gestão de dados para serem coletados, processados e armazenados.

Art. $7^{\circ} \mathrm{O}$ tratamento de dados pessoais somente poderá ser realizado nas seguintes hipóteses:

I - mediante o fornecimento de consentimento pelo titular; (...)

Art. 11. O tratamento de dados pessoais sensíveis somente poderá ocorrer nas seguintes hipóteses:

I - quando o titular ou seu responsável legal consentir, de forma específica e destacada, para finalidades específicas (BRASIL, 2018) 
Ambos pedem consentimento, o diferencial é a finalidade específica solicitada para os dados pessoais sensíveis. E além da diferenciação dos tipos de dados a nova lei exige a implementação de uma política de gestão de dados pessoais. Nesse sentido as empresas promotoras ou aderentes à uma promoção comercial devem ser capazes de demonstrar que são capazes de atender solicitações específicas de participantes, também nos termos da mesma lei.

Art. $9^{\circ} \mathrm{O}$ titular tem direito ao acesso facilitado às informações sobre o tratamento de seus dados, que deverão ser disponibilizadas de forma clara, adequada e ostensiva acerca de, entre outras características previstas em regulamentação para o atendimento do princípio do livre acesso:

I - finalidade específica do tratamento;

II - forma e duração do tratamento, observados os segredos comercial e industrial;

III - identificação do controlador;

IV - informações de contato do controlador;

V - informações acerca do uso compartilhado de dados pelo controlador e a finalidade;

VI - responsabilidades dos agentes que realizarão o tratamento; e

VII - direitos do titular, com menção explícita aos direitos contidos no art. 18 desta Lei.

$\S 1^{\circ} \mathrm{Na}$ hipótese em que o consentimento é requerido, esse será considerado nulo caso as informações fornecidas ao titular tenham conteúdo enganoso ou abusivo ou não tenham sido apresentadas previamente com transparência, de forma clara e inequívoca.

$\S 2^{\circ} \mathrm{Na}$ hipótese em que o consentimento é requerido, se houver mudanças da finalidade para o tratamento de dados pessoais não compatíveis com o consentimento original, o controlador deverá informar previamente o titular sobre as mudanças de finalidade, podendo o titular revogar o consentimento, caso discorde das alterações (BRASIL, 2018).

Pelo disposto na lei verifica-se uma finalidade bastante clara de defesa do consumidor, ecoando princípios do próprio Código de Defesa do Consumidor, para avançar a efetividade do direito à privacidade, intimidade e segredo. O protagonismo nas decisões sobre o uso de dados é claramente conferido aos titulares desses dados, no caso consumidores ou participantes de promoção comercial. Somente esses titularespode indicar quem e como permitirá o acesso a seus dados e estabelecer os limites do processamento por terceiros.

\section{CONCLUSÕES}

Tendo em vista o ambiente do comércio digital a coleta sistemática de dados tem o potencial de tornar as pessoas, apenas, mais uma peça em uma burocracia automáticae secreta, sem possibilidades de interferir no resultado das conclusões algorítimas. Isso gera a vulnerabilidade de ser possível oesmiuçamento de detalhes da vida privada por organizações, que podem tomar decisões, com base nesses dados, afetando indivíduos, mas sem que tenham conhecimento sobre o procedimento adotado ou qualquer possibilidade de reação.

A SEFEL está em posição privilegiada para contribuir para que esse ciclo vicioso de coleta, processamento e armazenamento sistemático e irresponsável de dados seja rompido. Por meio de autorização, fiscalização, normatização e homologação das atividades pode induzir o mercado a praticar uma política de proteção de dados pessoais mais efetiva e transparente. Como, por exemplo, exigindo o cumprimento das disposições legais a respeito de proteção de dados dos regulamentos das promoções comerciais.

Atualmente muito pouco tem sido exigido das empresas para garantir que não haja coleta, uso e armazenagem desses dados. De 50 promoções comerciais estudadas, e a grande maioria (47 
casos) não dispõem nos seus regulamentos detalhes sobre a política de dados.Em apenas 3 promoções há menção à responsabilidade pela gestão de dados deusuários ainda de forma incompleta. Os demais casos se limitam a fazer constar a autorização do uso de imagem e voz.

O Brasil já dispõe de proteção dispersa (Constituição, Código Civil, Código de Defesa do Consumidor) e a partir de 2020 também entrará em vigor lei específica sobre o tema proteção de dados. Além dissoa Diretiva Europeia de Proteção de Dados Pessoais também é aplicável no Brasil quando há dados de europeus ou manipulados por empresas europeias.

A proliferação do uso das promoções comerciais para coleta de dados, o crescimento do volume de negócios digitais e a crescente utilização de novas tecnologias para a publicidade pressionam para a existência de marcos regulatórios cada vez mais específicos o que demanda dos órgãos públicos, como a SEFEL, cobrança de que sejam observados preventivamente, estabelecendo assim um paradigma jurídico administrativo que possa servir de sustentáculo para que haja maior responsabilidade social corporativa e mais desenvolvimento tecnológico, de modo a contemplar as proteções de ordem econômica e das relações de consumo que envolvem o uso de dados decidadãos.

\section{REFERÊNCIAS}

ABBOTT, Kenneth W.; SNIDAL, Duncan. Hard and soft law in international governance. International Organization; Cambridge, [s. 1.], v. 54, n. 3, p. 421-456, 2000.

AMORIM, Celso. Brazilian Foreign Policy Under President Lula (2003-2010): an overview. Revista Brasileira de Política Internacional. Brasília. P. 214-240. Dezembro, 2010.

BARROSO, Luis Roberto. Colisão entre Liberdade de Expressão e Direitos da Personalidade. Critérios de Ponderação. Interpretação Constitucionalmente Adequada do Código Civil e da Lei de Imprensa. Revista de Direito Administrativo, [s. 1.], v. 235, n. 0, p. 1-36, 2004.

BEN JOR, Jorge; SIMONAL, Wilson. País Tropical - Jorge Ben Jor - LETRAS.MUS.BR. 1969. Disponível em: <https://www.letras.mus.br/jorge-ben-jor/46647/>. Acesso em: 20 out. 2018.

BITTAR, Carlos Alberto. Os Direitos da Personalidade - $8^{\text {a }}$ Ed. 2015. São Paulo, SP: Saraiva, 2015. Disponível em: <https://www.saraiva.com.br/os-direitos-da-personalidade-8-ed-20158620672.html>. Acesso em: 8 maio. 2018.

BRASIL, Congresso Nacional. L5.768/1971. Lei das oromoções comerciais e captação antecipada de poupança popular Lei 5.768/1971. . 1971.

BRASIL, Congresso Nacional. Lei 13.709/2018. Lei 13.709/2018 - Lei de proteção de dados pessoais. . 14 ago. 2018.

BRASIL, Congresso Nacional. LEI No 10.406. Código Civil. . 10 jan. 2002.

CANALTECH. Big data: como a informação pessoal se tornou uma moeda valiosa na internet - Internet. 2016. Disponível em: <https://canaltech.com.br/internet/bigdata-como-ainformacao-pessoal-se-tornou-uma-moeda-valiosa-na-internet-79947/>. Acesso em: 26 set. 2018.

CASTRO, Gleise de. Valor Setorial: Comunicação Corporativa - Reputação em Crise: Os Danos À Imagem Provocados Pela Falta de Ética e de Transparência. Editora Abril, São Paulo. P. 10. Novembro, 2015. 
CF. Constituição da República Federativa do Brasil. . 1988.

DE CASTRO, Julio Cesar Lemes. O consumo na era da interpelação algorítmica. In:

INTERCOM - SOCIEDADE BRASILEIRA DE ESTUDOS INTERDISCIPLINARES DA COMUNICAÇÃO 2018, Joinville, SC, Brasil. Anais... . In: 410 CONGRESSO BRASILEIRO DE CIÊNCIAS DA COMUNICAÇÃO. Joinville, SC, Brasil Disponível em: <http://portalintercom.org.br/anais/nacional2018/resumos/R13-1148-1.pdf>

DEBORD, Guy. A Sociedade do Espetáculo. Rio de Janeiro, Contraponto, 1997.

DENNY, Danielle Mendes Thame. Agenda 2030 e governança ambiental : estudo de caso sobre etanol da cana de açúcar e padrões de sustentabilidade como bonsucro. 2018c. UNISANTOS - Universidade Católica de Santos, Santos [Brazil], 2018. Disponível em: <http://biblioteca.unisantos.br:8181/handle/tede/4581>. Acesso em: 24 jun. 2018.

DENNY, Danielle Mendes Thame. Direito para o Marketing Digital. [s. 1.], 2018. a. Disponível em: <http://rgdoi.net/10.13140/RG.2.2.12108.10887>. Acesso em: 20 out. 2018.

DENNY, Danielle Mendes Thame. Direitos da personalidade. Sao Paolo

DINIZ, Maria Helena. Curso de Direito Civil Brasileiro 3. Teoria das Obrigações Contratuais e Extracontratuais. Edição: 33a ed. [s.1.] : Saraiva, 2017.

DOORLEY, John; GARCIA, Helio Fred. Reputation Management: The Key to Successful Public Relations and Corporate Communication. [s.1.] : Routledge, 2015.

DURKHEIM, Émile. As Regras do Método Sociológico (1895). São Paulo, Martins Fontes, 2007.

EASA, European Advertising Standards Alliance. Fake News and Online Disinformation POSITION PAPERDirectorate-General for Communications Networks, Content and Technology, , 2018. Disponível em: <http://www.easaalliance.org/sites/default/files/Fake\%20News\%20and\%20Online\%20Disinformation_Position\%2 OPaper_EASA_0.pdf>

EBIT, Nielsen Holdings Plc. Webshoppers edição 38 a primeiro semestre de 2018 . Brasil. Disponível em: <https://www.ebit.com.br/webshoppers>.

EDIMUNDO, Dias de Oliveira. Responsabilidade Social Corporativa no Brasil: Quem paga a conta? S.1.: Novas Edições Acadêmicas, 2014.

EU, European Prliament and Council. GDPR Regulation (EU) 2016/679 of the European Parliament and of the Council of 27 April 2016 on the protection of natural persons with regard to the processing of personal data and on the free movement of such data, and repealing Directive 95/46/EC (General Data Protection Regulation) (Text with EEA relevance)OJ L, 4 maio. 2016. Disponível em: 〈http://data.europa.eu/eli/reg/2016/679/oj/eng>. Acesso em: 20 out. 2018.

FILHO, Cândido Ferreira da Silva; BENEDICTO, Gideon Carvalho De; CALIL, José Francisco. Ética, Responsabilidade Social e Governança Corporativa. Edição: 3 ed. [s.l.] : Alínea, 2014.

GHIRALDINI, Marcel. Marketing digital para CIOs / Impactos da Lei de Proteção de Dados. São Paulo

IANNI, Octavio. Enigmas da Modernidade-Mundo. Rio de Janeiro, Civilização Brasileira, 2003. 
KEOHANE, Robert O.; NYE, Joseph S. Power and Interdependence in the Information Age. Foreign Affairs, [s. 1.], v. 77, n. 5, p. 81-94, 1998.

KLEIN, Naomi. Sem Logo: A Tirania das Marcas num Planeta Vendido. Rio de Janeiro, Editora Record, 2002.

KOTLER, Philip. Marketing 3.0: As Forças que Estão Definindo o Novo Marketing Centrado no Ser Humano. Rio de Janeiro, Elsevier, 2010.

LASCH, Christopher. O Mínimo Eu. São Paulo Editora Brasiliense, 1986.

LETOUZÉ, Emmanuel. Big Data para o desenvolvimento Publicação Cetic.br - Centro Regional para o Desenvolvimento da Sociedade da Informação. Brasília: Cetic.br - Centro Regional para o Desenvolvimento da Sociedade da Informação, 2018. Disponível em: 〈https://www.cetic.br/media/docs/publicacoes/6/Panorama_estendido_maio_2018_online.pdf>. Acesso em: 22 out. 2018.

MIT, Technology Review Custom; ORACLE. The Rise of Data Capital. USA. Disponível em: <http://www.oracle.com/us/technologies/big-data/rise-of-data-capital-wp-2956272.pdf>.

MONOCLE. Soft Power Survey 2016/2017. 2017. <https://monocle.com/film/affairs/soft-powersurvey-2016-17/>Acessoem: 11 out. 2018.

MORÍN, Edgar. Cultura de Massas no Século XX. Rio de Janeiro, Forense Universitária, 1997.

NASSER, Salem Hikmat. Fontes e Normas do Direito Internacional. Um Estudo Sobre a Soft Law. Edição: $2^{\text {a }}$ ed. São Paulo: Atlas, 2006.

NERY, Rosa Maria de Andrade; JUNIOR, Nelson Nery. Instituições de Direito Civil. Direitos da Personalidade. Edição: $1^{\mathrm{a}}$ ed. [s.1.] : Revista dos Tribunais, 2017.

NETO, Elias Jacob de Menezes; MORAIS, Jose Luis Bolzan De; BEZERRA, Tiago José de Souza Lima. O projeto de lei de proteção de dados pessoais no mundo do big data. $\mathrm{O}$ fenômeno da dataveillance em relação à utilização de metadados e seu impacto nos Direitos Humanos.

Revista Brasileira de Políticas Públicas, [s. 1.], v. 7, n. 3, 2018. Disponível em: <https://www.publicacoesacademicas.uniceub.br/RBPP/article/view/4840>. Acessoem: 22 out. 2018.

NYE JR, Joseph. Soft Power: The Means to Success in World Politics. New York, Public Affairs, 2004.

OLIVEIRA, Luis Fernando Lima De. Semeando a Sorte: Regulação Econômica, Tributação e Estímulo à Poupança no Mercado Lotérico Brasileiro. Brasília, , 2017. Disponível em: <https://www.esaf.fazenda.gov.br/assuntos/pesquisas-e-premios/premio-seae/copy_of_premioseae-de-loterias-2017/t1-2-1-luis-fernando-025.pdf>.

ROBERTS, Peter W.; DOWLING, Grahame R. Corporate reputation and sustained superior financial performance. Strategic Management Journal, [s. 1.], v. 23, n. 12, p. 1077-1093, 2002.

SCHWARTZENBERG, Roger-Gérard. O Estado Espetáculo. São Paulo, Círculo do Livro, 1977.

SEFEL, Secretaria de Acompanhamento Fiscal, Energia e Loteria. Loterias e promoções comerciais. 2018a. Disponível em: <http://fazenda.gov.br/assuntos/loterias-e-promocoescomerciais/loterias-e-promocoes-comerciais>. Acesso em: 6 out. 2018. 
SEFEL, Secretaria de Acompanhamento Fiscal, Energia e Loteria. Sistema de Controle de Promoção Comercial. 2018b. Disponível em:

<https://scpc.seae.fazenda.gov.br/scpc/promocao_consulta_publica.jsf>.

SILVEIRA, Sergio Amadeu Da. Tudo sobre tod@s. Redes digitais, privacidade e venda de dados. Sao Paolo: Sesc, 2017. Disponível em:

<http://www.livrariacultura.com.br/p/ebooks/ciencias-sociais/sociologia/tudo-sobre-tods111277605>. Acesso em: 22 out. 2018.

SOUZA, Allan Rocha De et al. Marcos legais nacionais em face da abertura de dados para pesquisa em saúde: dados pessoais, sensíveis ou sigilosos e propriedade intelectual. Rio de Janeiro, RJ: Fundação Oswaldo Cruz, 2018. Disponível em:

<https://www.arca.fiocruz.br/handle/icict/28838>. Acesso em: 26 set. 2018.

THE SOFT POWER 30. <https://softpower30.com/> Acesso em: 10 out. 2018.

TORQUATO, Gaudêncio. Tratado de Comunicação Organizacional e Política. São Paulo, Cengage Learning, 2010.

TOTVS. ERP da TOTVS - Simplificando seu Negócio! 2018. Disponível em: <https://www.totvs.com/>. Acesso em: 20 out. 2018.

VIGEVANI, Tulio; De OLIVEIRA, Marcelo F.; CINTRA, "Rodrigo. Política externa no período FHC: a busca de autonomia pela integração" in: Tempo Social. São Paulo. Novembro, 2003. 